\title{
'When politics comes into play, law is no longer law': images of collective legal consciousness in the UK, Poland and Bulgaria
}

\author{
Marc Hertogh" and Marina Kurkchiyan
}

\begin{abstract}
This paper examines the idea of a common European legal culture by exploring its foundational component, 'collective legal consciousness', in three EU states: the UK, Poland and Bulgaria. Using a comparative research design and a variety of methods of data collection, it suggests that, underneath the thin layer of EU consensus, there are some fundamental differences in perceptions of law. The evidence shows that legal ideas are infused with perceptions of the political system. This finding suggests that the creation of a shared European legal culture depends on the prior formation of a common transnational polity right across the EU, together with a sense of political identity and of trust in the legitimacy of the European political authorities. The paper also demonstrates the multilayered character of collective legal consciousness, allowing different images of law to co-exist, underpinned by the perception of the source with which each image is associated.
\end{abstract}

\section{Introduction}

Most legal discourses advanced by EU politicians are based on the idea that there is growing normative consensus across the continent about important legal values, including the rule of law. For example, in a recent policy document, the European Commission claims that there is agreement among Member States about the core meaning of the rule of law as 'a common value of the EU' and that the rule of law is 'unanimously recognized' as a 'common denominator' of the EU (European Commission, 2014, p. 2). These ideas suggest that a shared European 'rule of law' legal culture is either in the process of emerging, or is already in place. To support these views, they usually point to the national laws of Member States.

'Legal culture' is, however, a complex and multi-faceted concept (Nelken, I997; 2004; Cotterrell, I997; Friedman, 2006). In an attempt to make the concept empirically tangible, various authors have suggested distinguishing between its different layers and intertwined dimensions (see e.g. Blankenburg and Bruinsma, I994; Merry, 2010). But whatever model is proposed to separate the various components of legal culture, it is unquestionable that legal consciousness, understood as a cognitive image of law that is constructed through the life experience of people, is a principal component of the concept. In this paper, we scrutinise that particular dimension of legal culture, in order to demonstrate that legal reforms in EU Member States are not sufficient to create a common EU 'rule of law' culture. We examine the idea of a common European legal culture through the lens of legal consciousness (see also Gibson and Caldeira, I996) probing the ways in which people in the EU relate to law. Do they really share 'common values'? Do they recognise the value of the rule of law in their own country and in Europe? And which are the "common

\footnotetext{
* Professor of Socio-Legal Studies, University of Groningen, The Netherlands. E-mail: M.L.M.Hertogh@rug.nl. ** Senior Research Fellow, Centre for Socio-Legal Studies and Wolfson College, University of Oxford, UK. E-mail: marina.kurkchiyan@csls.ox.ac.uk.
} 
denominators' in their perceptions of law, if any? Using data from focus group discussions, national surveys and semi-structured interviews, the paper not only describes individual perceptions of law, but also examines the dominant 'collective legal consciousness' in three of the EU's Member States: the UK, Poland and Bulgaria.

In the next section, we present the research design and the methods used in this study. In Section III, we focus on people's perceptions of law and politics inside their home countries. We demonstrate that their conceptions of their own political systems echo their perceptions of law and of the qualities associated with that particular polity. Then, in Section IV, we examine common perceptions of law and politics in relation to the EU as a whole. It turns out that perceptions of how things work at the Europe-wide level are the reverse of perceptions at the domestic level. Next, in Section V, we analyse these findings. Our methodological focus on legal consciousness has revealed three important features about the way in which people perceive law: first, perceptions of law are, to a large extent, defined by perceptions of the political system; second, people in each country share their own distinctive pattern of collective legal consciousness; and, third, legal consciousness is a multidimensional phenomenon that combines different forms of 'inward' and 'outward' legal consciousness(es). In the final section of this paper (Section VI), we summarise and comment on our main conclusions. We reflect on some of the implications of the study, both for the analysis of European legal culture and for the EU's policy programme, aimed as it is at promoting a single rule of law culture in all Member States. We contend that, even if the EU can fully harmonise other dimensions of legal culture, such as law and institutional performance, across the EU countries, it would still be questionable whether a single European legal culture could be created. That would require the prior formation of an accepted common transnational polity, with a feeling of shared political identity, and trust across the EU in the legitimacy of the European political authorities.

\section{Research design}

\subsection{Collective legal consciousness}

Collective legal consciousness consists of a pattern of thinking among people about what law is and how they relate to it. In recent decades, the study of 'legal consciousness' has become a popular subject in socio-legal research, both in the US (Merry, I990; Ewick and Silbey, I998; Nielsen, 2000; Silbey, 2005) and in Europe (Cowan, 2004; Hertogh, 2004; 2009; Harding, 20Io; Halliday and Morgan, 2013). A growing number of books and papers have focused on 'individuals' experiences with law and legal norms, decisions about legal compliance, and ... the subtle ways in which law affects the everyday lives of individuals' (Nielsen, 2000, p. 1059). However, most of these studies have been directed at studying 'legal consciousness' as it exists in the mind of an individual person. This is not to say that it has only been approached as a person-by-person affair. On the contrary, its status as a group phenomenon is well recognised: a particular, legal consciousness has been attributed to people who have similar social experiences within a given society, such as the American working class (Merry, I990) or the 'welfare poor' (Sarat, I990), or 'collective voices of dissent' of radical environmental activists, studied by Halliday and Morgan (2013). However, this paper explores collective approaches to broader society.

All previous studies of legal consciousness have concluded that 'the way in which people perceive law and legality is a multilayered and dynamic construct, responsive to their surrounding social situation' (Kurkchiyan, 20II, p. 372). Building on those older findings, we take our analysis one step further. If legal consciousness is shaped by the societal context in which people live, then it is logical to ask whether social and political differences between societies will cause differences in their legal consciousness. If that is so, then, by taking a comparative approach, we should be able 
to uncover the differences of meaning that people attach to law in one country as distinct from another.

To analyse this in the three EU countries under study, we examine dominant perceptions of law and consider how these perceptions are related to the specific features of the social environment. Earlier research has suggested that, for our understanding of a public's collective legal consciousness, we should also take into account their perceptions of the political culture (Kurkchiyan, 20II, p. 383). In this paper, we will probe into this more closely. For example, do people suppose that they can influence the law-making process? Do they feel that the law-makers are accountable to them? Do they believe that they have at least some degree of control over the laws imposed on them? What are the mass public perceptions of politics? Do they trust their parliament and their government, and how are those views related to their wider perceptions of law? Evidence was collected on all these issues and more, and we analyse the resulting data on two levels: the domestic and European - first, what are people's perceptions of law and politics in their own country and, second, what are their perceptions of EU law and politics? The use of a comparative research design allows us to contrast the respective interpretations of law and politics in different societies. It enables us to identify what is unique about the way in which people construct concepts of law in their own social setting.

\subsection{Methodology}

In this paper, we examine collective legal consciousness in the UK, Poland and Bulgaria. In relation both to the EU and to domestic law and politics, the UK and Bulgaria are located at the two extremes of a sliding scale, with Poland in the middle. The UK is one of the oldest Member States of the EU (since 1973) and Bulgaria is one of the newest (since 2007), while Poland has been a member since 2004.

The paper draws its evidence from data that were originally collected as part of a broader project. ${ }^{\mathrm{I}}$ In each country, a 'mixed methods' approach was used, including focus group discussions, representative surveys and semi-structured interviews with legal professionals. First, eight focus group discussions were organised for each country, with the members of each selected with care so as to include different levels of education and income (2008). ${ }^{2}$ Next, nationally representative surveys were conducted with over I,000 people in each country (2009). ${ }^{3}$ Finally, twenty-five semistructured interviews were conducted in each country with local lawyers, each working in different legal fields and in different regions (2010). The focus group discussions, surveys and interviews all used a similar set of questions. They were designed to draw out the respondents' perceptions of law, such as 'What images and thoughts come to mind when we mention law?' and 'Is law important in daily life and if so, why and when?'. There was also a series of questions about the images people have about judges and politicians. The aim was to combine the data from all three methods to produce 'thick descriptions' (Geertz, I973; Nelken, 2004, p. Io) of the legal culture in each country. All data were collected in the local language and subsequently translated into English. Before presenting the data, we make some clarifying comments.

First, we focus only on the cognitive components of legal culture and of political culture. The data tell us what people perceive about the meanings and the roles of law in their lives, their views of their political system and the degree of confidence they have in it, about their social expectations, and about their interpretations of their legal and political environments. These perceptions were not

I Marina Kurkchiyan et al., Legal Cultures in Transition: The Impact of European Integration (Research Council of Norway, 2007-2012) (on file with the authors).

2 See Appendix for more information about the focus groups.

$3 \operatorname{UK}(N=\mathrm{I}, 20 \mathrm{I})$; Poland $(N=\mathrm{I}, 227)$; Bulgaria $(N=\mathrm{I}, 225)$. 
checked to see whether they were accurate, either factually or legally, and they were not used to examine how people actually behave.

Second, we focus on what we consider to be mainstream public views; some of that country's citizens have other views on law and politics, but they are not discussed here. Also, this paper focuses on the differences between the three countries in respect of their collective legal consciousness, but this does not mean that these countries are completely different from each other; in many ways, they are similar. However, the general differences in legal consciousness are significant, even though they might be small and subtle.

Finally, the data were collected in 2008-20I0. More recent events may have had an effect on perceptions of law and politics. Image construction is a dynamic process and collective legal consciousness is responsive to societal changes. However, the principal argument of the paper is about the interplay of legal and political thinking, and it stands regardless of recent developments on the ground.

\section{Perceptions of domestic law and politics}

Our data suggest that, in general terms, people in the UK, Poland and Bulgaria share broadly similar ideas about law. Narratives from the focus group discussions and the interviews in all three countries tell us that law is everywhere associated with the foundations of social order; that it is seen as a force that protects society from chaos and anarchy and - as a British respondent expressed it - 'because of law the days of stealing and murder, and rape, and pillage are over' (UK, 4$) \cdot{ }^{4}$ Law was consistently associated with establishing an appropriate code of conduct for all, together with rules and regulations for its application to specific cases.

The survey evidence demonstrates that the differences in the interpretation and normative expectations of what law is and what it should do were subtle, rather than dramatic. When people were presented with the word 'law', 30.9 per cent of respondents in the UK, 43.2 per cent in Poland and 39.9 per cent in Bulgaria thought of it primarily as a set of written rules and regulations. Also, roughly four out of ten people in all three countries associate the word 'law' with order and discipline. And again, in all three countries, both in focus group discussions and in responses to a survey question, most people link the word 'law' to justice and fairness. ${ }^{5}$

However, this consensus exists only in relation to a thin layer of perceptions. As soon as the conversation about law is contextualised and people refer to law in relation to their everyday life and personal experience, fundamental differences emerge in the three countries. It is then that perceptions of specific qualities of law become significantly different: its social value and importance, its centrality in organising everyday life in their society and its potential to help ordinary people when they are confronted by difficulties that they did not cause. For example, British people associated law much more than respondents elsewhere with common sense and with the need to balance the inevitable rights and wrongs in everyday life. For them, the law was there to give general guidance as to how to behave, rather than being an instrument of control. In contrast, when Bulgarians talked about law, they were clearly referring much more to legal texts that should effectively lay down instructions; for them, the law was infused with such concepts as obligation, discipline and compliance (see Kurkchiyan, 20II). To examine these and other differences in greater detail, we focus on each country separately.

4 Throughout this paper, quotations from the focus group discussions will be referred to as '(country, focus group number)' and quotations from the interviews will be referred to as '(country, i+interview number)' UK for United Kingdom, PL for Poland and BG for Bulgaria.

5 UK (80.9 per cent), Poland (74.7 per cent) and Bulgaria (76.7 per cent) said that they associate 'law' with justice and fairness. 


\subsection{UK}

In any society, people's views are not completely uniform on any topic. However, a careful reading of the transcripts of our focus groups, interviews and survey data demonstrates that each society undoubtedly has a dominant vision in the form of a shared understanding about the most important issues faced by the population. In the UK, it is apparent that both British law and its supporting legal infrastructure are seen as reliable most of the time; they provide security and coordinate social interaction:

'The law gives you confidence here in everyday life to go about the daily things. You can walk about at night.' (UK, 7)

'If you're not going to break any [law], it doesn't cause problems for you.' (UK, 8)

'You've got to have some parameters in everything you do. So, yes, you need freedom but you can't just have total freedom because people need walls to bounce off. So law is the wall to bounce off.' (UK, I4)

Other respondents compared the UK to other countries, usually with a feeling of superiority. There was common agreement, with statements such as 'A lot of countries I've been to, they shake my hand and say: you've got the best legal system in the world and we love it!' (UK, I4).

The general sense of satisfaction with the law of the land was not only felt by ordinary people, but was also evident in interviews with lawyers:

'I think England has a pretty good legal system. [T]here are always things that you could learn and develop but I think, as a whole, we're OK in this country.' (UK, irg)

'I think the system 99 per cent of the time is extremely fair. I don't think there's a country in the world that does 'trial by jury' like we do. Trials are fair. People get a fair hearing.' (UK, ig)

The survey data support these inferences from the focus groups and the interviews. In the UK, 66.3 per cent of respondents feel that, on the whole, the law is fair and 58.5 per cent believe that the law helps ordinary people. British judges also enjoy the trust of the people, being seen as central to the legal system. Moreover, 79.3 per cent describe their overall attitude towards judges as (very) positive and $7 \mathrm{r} .6$ per cent feel that judges are fair in their judgments.

However, what was remarkable is that all our conversations about law tended to slide from law into politics. This happened consistently and easily. Both in the focus groups and in the interviews, discussions about British law (and legal culture) were closely linked with discussions about British politics (and political culture). Some respondents were very cynical indeed about day-to-day politics. Criticism of all the mainstream political parties was common, such as 'What's the difference between Labour, Conservative and Lib Dem? Nothing' (UK, 6). In many conversations, people expressed their disappointment, not just in individual politicians or in national leadership, but even in the political process as a whole. Comments such as 'What they're trying to do now is outlaw happy hours, and I can't see why the law is doing that' (UK, 5) or 'It's supposed to be Prime Minister's question time. He never answers a question' (UK, I3) typified such attitudes.

However, in the British case, it is necessary to draw a distinction between disappointment with politics and confidence in the foundational principles of political order. Despite the shortage of respect for politicians, people still seem to have a deep-rooted faith in the overall parliamentary system. It is their confidence in the system that made people believe that:

'We have the power as people to change the situation. We can change the Government. We do have a voice as a people. We've done that before. We have to just act.' (UK, 6) 
'If you disagree with the law, you have to work within the system to get it changed, however much you disagree with it. It's a democracy, if you have enough support you will get it changed.' (UK, 8)

It should be stressed that the belief among British citizens that their voice has power and can make a difference was neither universal nor absolute. A few of the focus group participants were sceptical and questioned whether people do, in practice, have an influence on politics. The controversial introduction of the poll tax and taking the country to war in Iraq, despite mass protests against what was perceived to be the will of the people, were the two examples most frequently cited. However, such sceptical views were usually challenged by other participants:

'People have tried [to change the law]. When the poll tax came in they tried holding out, demonstrating and not paying. Even old ladies got thrown into prison for that.

'But they got the law changed. They got the government chucked out in the end.' (UK, I2)

Overall, despite frustrations and disengagement from the political process, people felt that they had a variety of channels through which they can effectively be part of the political process if they wish to:

'You should tell your local MP, because they are the ones that speak for us, that's why we elect them to do things, and they go and speak for all of us.' (UK, 4)

'That's keeping within your, you know, democratic boundaries sort of thing. You can't just go out and start protesting in a violent way. I think the only way is in a provincial forum or to lobby your MP.' (UK, I I)

These impressions were supported by the survey evidence. For example, when asked what you should do if parliament passed a law that some people felt was really unfair and unjust, a large majority of respondents in the UK (74.3 per cent) felt that they should protest against the law (e.g. by taking it to their local MP). Overall, almost seven out of ten people in the UK (66.3 per cent) felt that, on the whole, the law is fair and that the law generally helps ordinary people (58.5 per cent); 62.2 per cent agreed (strongly) that the government and parliament can be trusted to draft clear and effective laws. Moreover, people felt that they can influence the law-making process and that they have some level of control over law imposed on them.

\subsection{Poland}

The narratives of the discussions in Poland suggested different perceptions about law. The Polish discussants presented the legal domain as a risky social space that should be avoided if at all possible. For them, it was an arena in which problems are generated, rather than solved; law is a trouble-making force and the legal institution is unreliable and untrustworthy. This is how some participants in the Polish focus group discussions spoke about law:

'The law is created to screw ordinary people, pardon my French. Because the law is not for us, it is not meant for most Poles.' (PL, I)

'When I think about the law, I think about some direct risks for me.' (PL, 3)

'The entire legal system in Poland is sick. The judges, and public prosecutors and the police and all forces are sick; it should be changed right from the start.' (PL, I)

However, the survey data offset slightly the hostile perception of the legal institution conveyed by the participants of focus groups. It shows that, although an inimical image of law is indeed dominant in Poland, and four out of ten people (39.7 per cent) feel that the law makes problems for ordinary 
people, there still remain three out of ten people (32.4 per cent) who think that, on the whole, the law is fair.

One would expect that legal professionals would have an urge to defend their role and would be inclined to project a more positive image of the institution. Yet, according to our interviews, their perceptions were not very different from those shared by the majority of lay people, although their reasoning was different:

'I do not have much faith in the Polish judiciary, it's just I have seen too much. I prepare detailed documentation, I search for rulings passed by Polish and European courts, and then the court confuses the names of persons who are taking part in the proceedings, and ignores my work on which I put a lot of effort.' (PL, ir3)

In Poland, we found one pronounced similarity to the findings in England. In both societies, discourses on legal issues were blended so closely with political issues that it became problematic to distinguish between them even for analytical purposes. To explain and justify their views on law and the Polish legal system, people frequently referred to what is happing in the political sphere. Equally, comments on politics in the focus groups would quickly merge with issues of the quality of law, law-making, legality and justice. This link was explicitly acknowledged by the participants themselves:

'I think that our legal system may be inefficient but it's not the worst one under the sun. It all depends on the central bodies, the parliament, the government, those who create the law.' (PL, 6) 'If law was law and nothing else, no politics, it could function well, but when politics comes into play law is no longer law.' (PL, 8)

Transcripts of the discussions in Poland indicate that public trust in politicians and government is in deficit. People are sceptical, both about the political establishment and the way their country is run. Those views are exemplified by comments such as 'I do not trust either the Government or Parliament when it comes to law-making, since this process in Poland is completely incompetent, ineffective, bungled and trashy' (PL, 2).

However, it was apparent that the mass frustration in Poland went beyond disillusionment with whoever happened to be in government or the legislature at any particular time. Distrust went deep into the roots of the political system. People did not believe that ways were open to them to influence political decisions or that there were means to make law-makers accountable: 'People should have the opportunity to gather together with petitions and motions, to fix that law. But people, as the society, do not have enough access to whatever the government is doing' (PL, 2).

The public's low level of trust in political institutions in Poland is sharply exposed by the survey data. For example, 70.3 per cent of the population thought that both government and parliament are too favourable towards the rich and powerful. Also, many of them (62.6 per cent) believed that politicians habitually draft laws for their own personal advantage, rather than for the good of the country. Even more importantly, many people believed that lack of respect for law is strongest within the political establishment: 70 per cent of the respondents thought that members of parliament are less law-abiding than ordinary people, and more than half (55.6 per cent) thought that, unlike ordinary people, politicians would feel powerful and self-confident while they are in the act of breaking the law and that there is no mechanism in the political machinery to make the powerful accountable. 


\subsection{Bulgaria}

For ordinary people in Bulgaria, the perception that there was disconnect between law and the everyday life of ordinary people was even more pronounced than in Poland. Law was seen as a powerful instrument in the hands of the rich and powerful. That theme was repeatedly asserted in both interviews and focus groups:

'There is a simple truth that we are all aware of - the law is for the rich and the penalties are for the poor.' (BG, I)

'Unfortunately, the law is only for people who have no other option but to abide by it. But it does not apply to the bigwigs. If something happens to an ordinary person and to a celebrity, the first one goes to jail and the second is above the law.' (BG, 2)

The Bulgarian public's dominant view of the legal system was that:

'the Bulgarian court is very slow, clumsy, and corrupt.' (BG, IO)

'the judiciary is politically dependent.' (BG, Io)

'it is not important what the level of the judges in Bulgaria is (regional or higher instance), because everything is still solved with money.' (BG, 3)

Furthermore, 'some [judges] participate in the crimes along with the criminals. ... The only difference is they are dressed in gowns' (BG, 2). The shared antipathy in Bulgaria in relation to the legal domain can be summarised in a statement made by a focus group participant: 'You put your hand on the book and make an oath to tell the truth, and nothing but the truth, and then the truth dissolves' (BG, 9).

To put this view into a broader social context by reference to survey data, 74 per cent of respondents felt that judges in Bulgaria pay too much attention to whether the government will be pleased or displeased by their rulings in court; and only 37.6 per cent feel that judges in Bulgaria are fair in their judgments. In Bulgaria, nearly five out of ten people (48 per cent) feel that the law reflects the power of the state to control people.

The usual way in Bulgaria to explain their apparent legal nihilism was to refer to politics and politicians. These are some illustrations of how their perception of law is influenced by their perception of politics (and vice versa):

'Unfortunately, in our country the lawmakers are the ones that do not observe the laws.' (BG, 6)

'Our laws were made by the Great National Assembly only to serve their private interests.' (BG, 2)

Overall, a significant majority of respondents (77 per cent) thought of members of parliament as less law-abiding than ordinary people. A large majority (75.9 per cent) believed that members of both government and parliament in Bulgaria tend to draft laws for their own personal advantage, rather than for the good of the country. Also, most of them (80.3 per cent) feel that government and parliament as a whole are too favourable towards the rich and powerful. The entire political and legal system in Bulgaria was perceived as a self-reproducing structure of corruption. For example, 78.5 per cent of those surveyed said that the members of both the government and the parliament in Bulgaria are willing to take bribes. Among focus group participants, there was a strong feeling of powerlessness and alienation from what was happening in the country: 
'People comment - on the bus, in the café, everywhere. And very often it stays down there. There is nothing we can do. While those in Parliament only hear what people think at election time. After they get elected, they forget what people told them, until the next election.' (BG, 3)

\section{Perceptions of EU law and politics}

People in Poland and Bulgaria had radically different views from those in the UK about the EU and EU law. For example, both in Poland (83.3 per cent) and in Bulgaria (84 per cent), most of the people surveyed felt that their country should be a member of the EU. In the UK, that was only true of half of the respondents (49.8 per cent). Also, people in Poland (74.4 per cent) and in Bulgaria (82.I per cent) felt that their domestic law should be based on international standards, such as those set by the EU. In the UK, this view was considerably less popular, held by only 53.7 per cent. To examine these and other differences, we once again examine each country individually.

\subsection{UK}

In the UK, almost half of the respondents who participated in the survey (43.6 per cent) felt that EU laws had caused unnecessary problems for ordinary people. They imposed rules and regulations that were considered to be useless or even laughable, and not suited to the British context. This sentiment was expressed in a variety of forms, but always along the same lines:

'I think in a legal sense Europe is very, very bad news for us. I really do.' (UK, I4)

'Talking about the law; the EU laws - that's a prime example of something that does irritate me.' (UK, 6)

'They impose silly things sometimes, the EU. That, you know, aren't relevant at all. What was all that about the metric thing? There was a guy who got arrested for selling bananas as pounds instead of kilos or something? That's stupid.' (UK, 3)

Evidently, there was a clear distinction in people's minds between 'our' law and law that had originated 'somewhere else', regardless of its actual content or quality. As discussed in the previous section, most people in the UK seemed fairly positive about domestic law and their own legal system. Consequently, they did not feel that the UK could learn much from the laws of the EU or the laws of other countries. The dominant view was that it is the other way round. They should look at ours that has been set in stone and has worked for years and years' (UK, I 2). The very idea that there might be good EU laws that work successfully across many countries did not make sense to many people. Two-thirds of the UK respondents (67.8 per cent) thought that their country should have different laws, applied in ways that better suit their country and people. As a participant of a focus group put it: 'The problem with Europe is that it is so big and covers so many different cultures that laws have to be a catch-all to cover everybody's culture and it doesn't usually fit' (UK, I2).

The same distinction between 'our' law, which is rational and should be treated as a social good, and 'their' law, which is unfit, not thought through and generally useless if not damaging in the UK context, was also shared by British legal professionals. In our interviews, they articulated this notion clearly:

'We Brits really don't like being told what to do. I think some of the legislation that comes in from Europe, which is based on a different Code, is a bit nannyish, it's a bit bossy, and we don't really like it.' (UK, i5) 
'I think we are probably more the teacher than the student on that.' (UK, i2o)

'I think here in the UK, we've got it right and I'd like to see us remain in our laws.... I think our laws suit us very well. If anything, Europe should follow us.' (UK, ig)

'Let's put it this way, if they have ours that is great. If we have to have theirs I'm not so sure.' (UK, ir 3 )

In the same way as the patterned responses that we noted in the section on the domestic context, these conversations about EU law were shaped by conversations about EU politics. Having dismissed EU law and the role that it might play in their own country, most people in the UK went on to express their distrust of the political system of the EU and what they considered to be its unrepresentative governing institutions. They generally did not believe that they had, or ever could have, any influence on the law-making process in Brussels; and they did not feel that they exert control over the laws imposed on them:

'We should govern our own country, I reckon.' (UK, 4)

'I think that the key point is that we voted in a Government in the UK, but we have absolutely no say in who makes up the EU and who makes these decisions; so these are being imposed on us.' (UK, I4)

'The thing is, if we're going to accept laws that come from Europe, why do we need our Parliament?' (UK, 5)

\subsection{Poland}

In Poland, people generally welcomed EU laws and regulations. For example, 64.I per cent felt that EU laws help to protect ordinary people from bad laws that might be made by their own government, and shared the view that 'the EU has brought a lot of good things to Poland' (PL, i3). Both in the focus group discussions and in the interviews with legal professionals, people argued that the EU has been important for the development of Poland:

'Order is being introduced into our law, the law is entering a higher level of citizen service .... The influence of international law makes both the Highest Court and the legislature introduce $2 \mathrm{I}^{\text {st }}$ century changes.' (PL, i2 I)

'Without the European Union, I think it would be total anarchy in this country.' (PL, I)

The goal of progressively harmonising laws all the way across the EU was supported by lay people and legal professionals alike. The idea that their country should broadly have the same laws as the rest of Europe was backed by the majority. In a widely supported view, one lawyer remarked that 'a unified legal system in all European countries would facilitate the effective settlement of disputes and also the regulation of ordinary citizens' lives' (PL, i2 I).

This image of the desirability of potent EU law was well supported by equally positive views about the EU political process. In Poland, most people (88.8 per cent) felt that their country had a lot to learn from other countries and from European and other international organisations about how to write good laws. Most of them (83.9 per cent) also felt that Poland could learn from organisations like the EU about the way that political leaders should themselves respect the law. It was believed that the EU (and international law in general) could promote the legal and political reform that Poland needed in order to stamp out corruption: 'In some cases international law should force our government to display proper behaviour' (PL, I).

What was remarkable in the narratives of the discussions and interviews was the extent to which people generally felt that they had a say in the European law-making process and that EU law 
possessed a high degree of legitimacy, which had been obtained through a democratic process. They did not think that EU laws were being imposed on them against their will. Instead, the typical argument was that:

'In my opinion we have decided upon being subject to the EU in a referendum. It was the voice of society.' (PL, iro)

'I haven't noticed that the [European] norms which we adopt were inconsistent with our feelings and the feelings of our society.' (PL, iI5)

\subsection{Bulgaria}

Just as in Poland, most people in Bulgaria felt that EU laws and regulations were beneficial to them. It was believed that:

'it's very good that Bulgaria joined the EU and belongs to the European States. If we want to catch up with them, we have to enforce the laws like they do and have similar laws to theirs. I hope that is going to happen.' (BG, 4)

For the Bulgarian public, having Bulgarian law integrated with EU law and even subordinated to it would only serve to strengthen legality in the country, making everyday life easier and generally serving to promote social progress. Both in the focus groups and in the interviews, participants gave examples that illustrate how EU law had already helped them in their daily lives:

'For example, the European requirements about the production of food, electrical appliances etc. I think this is good. One feels more secure when they bear the quality mark.' (BG, 4)

'The law for protection of the environment. This has not been considered an issue until now. It is new and was introduced with the European directives.' (BG, 3)

Overall, 63.6 per cent felt that EU laws help to protect ordinary people from bad laws that might be made by their own government. Also, 55.5 per cent thought that Bulgaria should broadly have the same laws and law enforcement as the rest of Europe.

These positive images of the EU laws corresponded with equally positive views about the performance of the EU's governing institutions. A large majority (83.3 per cent) felt that Bulgaria had a lot to learn from the EU (and from other international organisations too) on matters of law and legality. In the focus group discussions, people explained that the EU membership would promote important legal and political reforms in Bulgaria and impose control over corrupt politicians at home. As one participant put it, 'they are all the same gang in the parliament [in Bulgaria]. I believe there should be some other type of control'. This optimistic view was shared by 79.2 per cent of Bulgarian survey respondents, who expressed the hope that pressure from the EU might reduce the level of corruption in their country.

Just as in the pro-EU perceptions described so forcefully in the Polish focus groups, Bulgarians believed that supremacy of the EU law over domestic law was fully legitimised by the mass vote that had formalised agreement to EU membership by the majority of the people. They shared the trust that the Poles had shown in the referendum as a political device, viewing it as a powerful tool in the democratic process. It was emotionally defended in one focus group: 'Referendums! People's control of government and parliament through referendums and control from the EU' (BG, 3). 


\section{Discussion: revisiting legal consciousness}

Looking back at our findings, we can infer three important features of the way in which people perceive law. All three elements contribute to a deeper understanding of collective legal consciousness as a social phenomenon, and all three have implications for diversity among the various legal cultures of Europe.

\subsection{Legal consciousness is closely connected to perceptions of the political system}

First, the study suggests that people's legal ideas and expectations are not isolated values, but instead are strongly influenced by the local context. More particularly, the focus group discussions and the interviews demonstrate that the public's perceptions of law are moulded by political culture. This is not only true when people express how they see domestic law and the national political system, but also when the discussion shifts to EU law and the EU political system.

The survey data support these inferences from the focus groups and the interviews. It shows a strong correlation between indicators of legal and political cultures across countries in relation to both domestic and European law. Expressions of legal nihilism usually come together with political cynicism, and vice versa. Perceptions of law as a positive social good, which can be expected to deliver justice, tend to co-exist with trust in the political system. For example, among people who feel that the law in their country generally makes problems for people like themselves, a large majority (67.3 per cent in UK; 8I per cent in Poland; 9I.I per cent in Bulgaria) also agree (strongly) that their government and parliament draft laws for their own personal advantage or business interests, rather than for the good of the country. Conversely, only a small minority of those with dismissive views of law as unhelpful would admit to a positive expectation about the performance of the political rulers (32.7 per cent in UK, I9 per cent in Poland, 8.9 per cent in Bulgaria). The same pattern is repeated in relation to EU law: among people who feel that EU standards, laws or regulations cause problems rather than providing benefits for ordinary people; a majority (67.4 per cent in UK; 70 per cent in Poland, 77.6 per cent in Bulgaria) would also prefer that their country should withdraw from the EU.

Inferences from our focus group discussions suggest that there are at least three different ways in which conversations about law are connected to conversations about politics. First, the political system is considered to be an important source of the law. For this reason, people's perceptions of law are shaped by their level of trust in the political authorities that are regarded as the source of law, generally parliaments and governments. Second, an effective political system is considered to be an important condition for legal reform. This means that the image of law held by ordinary citizens is influenced by their degree of confidence in the political system more broadly and not just by their attitudes towards whoever currently forms the ruling elite. Finally, the image of law is shaped by whether or not ordinary people believe that popular involvement in the law-making process is a genuine possibility and not mere empty propaganda. Whether people feel that they have some level of control over the law depends on their sense of the responsiveness of the political system.

In short, all three elements suggest that 'legal consciousness' is closely linked to 'political consciousness'. Perceptions of law are not just shaped by first-hand personal experience of law or the relevance of law to personal interests, but also by a broader interpretation of the political process, and - even more so - by the degree of trust that they have in the foundations of their political system.

\subsection{From individual to collective legal consciousness}

The fact that people's perceptions of law are shaped by their social environment also highlights a second feature of legal consciousness. Most previous studies examine legal consciousness from an individualistic perspective, which is then generalised for social groups within society, such as 
socio-economic classes. By contrast, our use of a comparative approach gives a description of views that prevail across society. It examines the dominant legal consciousness prevailing among the populations of Poland, Bulgaria and the English part of the UK, respectively. Considering that, in all three countries, perceptions of law are strongly defined by perceptions of the political process and, considering also the fact that these people share the same national political system, our study suggests that people in each country develop their own distinctive pattern of collective legal consciousness.

\subsection{Inward and outward legal consciousness}

Legal consciousness is not a monolithic vision of 'the' law in general, however, as it is sometimes presented. It has a multidimensional character and what is true for one law may not be true for other laws. Following Engel's (I998, p. I40) observation that 'different substantive areas of law are associated with different perceptions, understandings, and behaviors', our study suggests that collective legal consciousness is also layered according to the source with which it is associated. In particular, we found important differences between 'inward' legal consciousness (of domestic law or 'our' law) and outward' legal consciousness (in our case, of EU law or 'their' law). To describe the differences, it is helpful to adopt a typology suggested by Ewick and Silbey (I998) of how people relate to law: subjects can be 'before the law', impressed by its majesty and convinced by its legitimacy; 'with the law', utilising it instrumentally and generally understanding it as a game; or 'against the law', cynical about its legitimacy and distrustful of its implementation. In addition, Halliday and Morgan (2013) point to cases in which people can feel strongly about an abstract concept of legitimacy that in their mind stands above the actual law of the land that has been produced by the state. When we apply this typology to our data, we see some important differences in what law means to people at a societal level.

Undoubtedly, all these ways to relate to law co-exist in all societies, creating some tension at the level of collective, societal, legal consciousness. However, one can identify a dominant way of thinking for each case. In the UK, people's perceptions of domestic law can be characterised as predominantly 'before the law', whereas their perception of EU law is best described as 'against the law'. This is the mirror image of the other two countries. While, in Poland and Bulgaria, people's perceptions of domestic law may be characterised as 'against the law', their perception of EU law is best described as 'before the law'. As was suggested earlier in this paper, these differences cannot be fully explained as different ideas and expectations of the law, alone, but they can be related to the differences in the general perceptions of the political systems, domestic and European.

\section{Conclusion}

In this paper, we have addressed the assumption that a common European legal culture can be achieved by institutional reforms and harmonisation of laws across the EU. We designed our enquiry by comparing one of the foundational components of legal culture, 'collective legal consciousness', in three EU countries: the UK, Poland and Bulgaria. Our use of a comparative research strategy in three countries allows us to make generalisations about patterns of collective legal consciousness, which have implications both for EU policy and for future socio-legal research.

The findings indicate that, in general terms, people in all three countries share similar ideas about law. However, the consensus represents only a thin layer. Underneath, there are some fundamental differences in perceptions of law. In our view, this may be explained by the fact that legal ideas and interpretations are not isolated values, but are closely connected with views about the political system. Perceptions of law are shaped not only by the perceived fairness of the legal process, but also by the perceived fairness of the political process and the degree and extent of trust in the principles on which it stands. This is not only true in a national context ('our' law and 'our' 
political system), but also in a transnational context (EU law and EU political organisation). In other words, legal consciousness is immersed in perceptions of the political system.

From the policy perspective, we argue that the current programme to promote European values of respect for law, legality and human rights in all Member States, by exclusively focusing on the 'rule of law' reforms (European Commission, 20I4) is not sufficient. The existence of a strong link between legal consciousness and political consciousness suggests that future EU policy must adopt a much wider perspective - one that is not restricted to the legal systems, but also monitors the political process in all countries of the EU. It needs to project a much more democratic image of its political structure, while at the same time cultivating a stronger identity of European political citizenship across its Member States.

We are not in a position to assess whether at the present time we are witnessing convergence or divergence among the legal cultures of the various EU countries. For that purpose, more recent data are needed, drawn from research in a larger number of countries. Moreover, in this study, we focused exclusively on collective legal consciousness, which is only one of the dimensions of legal culture. In order to gain a better understanding of the dynamics of the legal cultures in the EU countries, future comparative research should also look at the institutional and behavioural dimensions of the concept.

Our findings also contribute to a deeper understanding of legal consciousness at all levels: individual, group and societal. Most previous studies of legal consciousness have been based on a conceptual framework focused on 'law' and the 'legal'. Although the importance of the political context and the way in which people position themselves in relation to the state have been considered as factors that shape legal consciousness, as in the study by Halliday and Morgan (2013), such studies have treated the political setting only as a structural background. On the other hand, when legal consciousness has been approached from a legal culture perspective, political factors often got lost within an over-generalised notion of 'social forces', which drive either towards the law or away from it (Friedman, I975, p. I94). In contrast, we suggest that legal and political consciousnesses are firmly linked together and that a deeper understanding of the 'legal' dimension of everyday thinking requires more careful and detailed study of its interplay with the 'political' dimension. The political dimension can present itself in different forms, such as trust in the foundations of the system, attitudes to current political affairs, and a sense of having personal power to participate in political processes and even to exert some control over them.

\section{References}

Blankenburg, Erhard and Bruinsma, Freek (I994) Dutch Legal Culture, 2nd edn. Deventer: Kluwer Law and Taxation Publishers.

COTTERRELL, Roger (1997) 'The Concept of Legal Culture' in David Nelken (ed.) Comparing Legal Cultures. Aldershot: Dartmouth, I3-3I.

cowan, David (2004) 'Legal Consciousness: Some Observations', Modern Law Review 67: 928-958.

ENGEL, David (I998) 'How Does Law Matter in the Constitution of Legal Consciousness?' in Bryant

G. Garth and Austin Sarat (eds) How Does Law Matter? Evanston: Northwestern University Press, I09-I44.

European Commission (2014) Communication from the Commission to the European Parliament and the Council: A New EU Framework to Strengthen the Rule of Law. COM (2014) I58 Final. Brussels, I I March 20I4. Available at <http://ec.europa.eu/justice/effective-justice/files/com_20I4_I58_en. pdf $>$.

EwICK, Patricia and SILbey, Susan (1998) The Common Place of Law: Stories from Everyday Life. Chicago: University of Chicago Press.

friedman, Lawrence (1975) The Legal System: A Social Science Perspective. New York: Russel Sage Foundation. 
FRIEDMAN, Lawrence (2006) 'The Place of Legal Culture in the Sociology of Law' in Michael Freeman (ed.) Law and Sociology. Oxford: Oxford University Press, I85-199.

GEERTZ, Clifford (I973) The Interpretation of Cultures: Selected Essays. New York: Basic Books. GIBSON, James L. and CALDEIRA, Gregory A. (I996) 'The Legal Cultures of Europe', Law \& Society Review 30: $55-85$.

HALliday, Simon and MORGan, Bronwen (2013) 'I Fought the Law and the Law Won? Legal

Consciousness and the Critical Imagination', Current Legal Problems 66: I-32.

Harding, Rosie (2010) Regulating Sexuality: Legal Consciousness in Lesbian and Gay Lives. London:

Routledge.

HeRTOGH, Marc (2004) 'A "European” Conception of Legal Consciousness: Rediscovering Eugen

Ehrlich', Journal of Law and Society 3I: 457-48I.

HERTOGH, Marc (2009) 'What's in a Handshake? Legal Equality and Legal Consciousness in the

Netherlands', Social \& Legal Studies I8: 22 I-239.

KuRKChiyan, Marina (20II) 'Perceptions of Law and Social Order: A Cross-National Comparison of

Collective Legal Consciousness', Wisconsin International Law Journal 29: 366-389.

MERRY, Sally Engle (I990) Getting Justice and Getting Even: Legal Consciousness among Working-Class

Americans. Chicago: University of Chicago Press.

MERRY, Sally Engle (2010) 'What Is Legal Culture: An Anthropological Perspective', Journal of

Comparative Law 5: 40-58.

NELKEn, David (ed.) (I997) Comparing Legal Cultures. Aldershot: Dartmouth.

NELKEn, David (2004) 'Using the Concept of Legal Culture', Australian Journal of Legal Philosophy 29: I-26. NIELSEn, Laura B. (2000) 'Situating Legal Consciousness: Experiences and Attitudes of Ordinary

Citizens about Law and Street Harassment', Law \& Society Review 34: I055-1090.

SARAT, Austin (I990) “The Law is All Over”: Power, Resistance, and the Legal Consciousness of the

Welfare Poor', Yale Journal of Law and the Humanities 2: 343-379.

SILBEy, Susan S. (2005) 'After Legal Consciousness', Annual Review of Law and Social Science I: 323-368.

\section{Appendix: Focus group locations and compositions}

\section{UK}

\begin{tabular}{lll}
$\begin{array}{l}\text { Group } \\
\text { number }\end{array}$ & Location & Target group \\
\hline I & London & Better educated \\
2 & London & Worse educated \\
3 & Bristol & Cross-section \\
4 & Yate & Cross-section \\
5 & From villages in south-west England: Almondsbury, Winterbourne Coalpit, & Cross-section \\
6 & Old Sodbury & Cross-section \\
7 & Sheffield & Cross-section \\
8 & From villages in northern England: Eckington, Ben Rhydding, Dronfield, & \\
\hline
\end{tabular}




\section{Bulgaria and Poland}

\begin{tabular}{|c|c|c|c|c|c|}
\hline \multicolumn{3}{|c|}{ Bulgaria } & \multicolumn{3}{|c|}{ Poland } \\
\hline $\begin{array}{l}\text { Group } \\
\text { number }\end{array}$ & Location & Target group & $\begin{array}{l}\text { Group } \\
\text { number }\end{array}$ & Location & Target group \\
\hline I & Sofia & Worse educated & I & Warsaw & Worse educated \\
\hline 2 & Sofia & Better educated & 2 & Warsaw & Better educated \\
\hline 3 & Opanets & Cross-section & 3 & Katowice & Cross-section \\
\hline 4 & Topoly & Cross-section & 4 & Turosn Koscielna & Cross-section \\
\hline 5 & Aksakovo & Cross-section & 5 & Mierzecice & Cross-section \\
\hline 6 & Pleven & Cross-section & 6 & Lubliniec & Cross-section \\
\hline 7 & Pleven & Cross-section & 7 & Zambkow & Cross-section \\
\hline 8 & Varna & Cross-section & 8 & Biakystok & Cross-section \\
\hline
\end{tabular}

